\title{
AS DIFERENTES PRÁTICAS DE CONTAGEM ENTRE OS GUARANI E KAIOWÁ: ELO ENTRE EDUCAÇÃO ESCOLAR E EDUCAÇÃO INDÍGENA NA FORMAÇÃO INICIAL DE PROFESSORES DE MATEMÁTICA
}

\author{
MARIA APARECIDA MENDES \\ Mestra em Educação Matemática pela Universidade Federal de Mato Grosso do Sul. Professora Assistente \\ da Faculdade Intercultural Indígena. E-mail: mariaoliveira@ufgd.edu.br \\ HEIRACLES MARIANO DIAS BATISTA \\ Mestra em Educação. Professora da UFGD. FAIND do Curso Licenciatura Intercultural Indígena Teko \\ Arandu. E-mail: heiradias@ hotmail.com
}

\section{RESUMO}

O objetivo deste trabalho é compreender as formas de contagem vivenciadas nas práticas sociais e culturais dos Guarani e Kaiowá de Mato Grosso do Sul e apontar possibilidades pedagógicas para o ensino da matemática nas escolas indígenas. O conhecimento da realidade desses povos fortalece as relações entre os atores (professores, alunos, universidade, escola e comunidade) na formação inicial de professores indígenas de matemática. O diálogo entre os conhecimentos indígenas e acadêmicos, que têm influenciado no ensino da matemática nas escolas indígenas e na formação de professores, configura-se como ponto de interesse neste trabalho. $\mathrm{O}$ espaço de formação inicial e a reflexão das ações desenvolvidas nele pressupõem a formação do professor como pesquisador das próprias práticas e possibilita uma compreensão dos diferentes aspectos no ensino-aprendizagem na escola indígena. A pesquisa, de cunho etnográfico, centraliza nas práticas de numeramento, na perspectiva da etnomatemática. Os dados foram produzidos, durante o processo de formação realizado no curso de Licenciatura Intercultural Indígena "Teko Arandu", pelos acadêmicos nas áreas indígenas as quais pertenciam. Foi possível perceber que diferentes formas de representação dos processos de contagem dessas etnias, relacionadas às práticas laborais, relações com a sociedade do entorno e formas de escrita escolarizada. Muitos desses conhecimentos ficam no universo da cultura e das práticas sociais e são pouco utilizados no processo de ensino e aprendizagem nas escolas indígenas.

Palavras-chave: Conhecimentos tradicionais indígenas. Educação matemática. Formação docente.

\section{PRACTICES BETWEEN DIFFERENT COUNTING THE GUARANI AND KAIOWÁ: LINK BETWEEN EDUCATION SCHOOL AND EDUCATION INDIGENOUS IN INITIAL FORMATION OF MATHEMATICS TEACHERS}

\begin{abstract}
The objective of this work is to understand the ways of experienced count on social and cultural practices of the Guarani and Kaiowá of Mato Grosso do Sul and point pedagogical possibilities for formation mathematics in indigenous schools. The knowledge of the reality of these people strengthens relations between the actors (teachers, students, university, school and community) in the initial formation of mathematics indigenous teachers. The dialogue between indigenous knowledge and academics, who have influenced in mathematics education in indigenous schools and teacher formation, is configured as a point of interest in this work. The initial formation space and the reflection of the actions developed it presuppose the formation of the teacher as researcher of the practices and enable an understanding of the different aspects of the teaching and learning of indigenous school. The ethnographic research centered on numbering practices from the perspective of ethnomathematics. The data were produced, during the training process carried out in the course
\end{abstract}


of Indigenous Intercultural graduation "Teko Arandu", by the academics in the indigenous areas that belonged. There are different forms of representation of the counting processes of these ethnic groups, related to labor practices, relations with the surrounding society and forms of schooling writing. Many of these skills are in the universe of culture and social practices and are little used in the process of teaching and learning in indigenous schools.

Keywords: Indigenous traditional knowledge. Mathematics education. Teacher training.

\section{Introdução}

O diálogo decorrente da ação entre diferentes formas de conhecimentos, tradicionais (conhecimentos próprios) e científicos, tidos como universais e que se apresentam escolarizados, tem influenciado no ensino de matemática nas escolas indígenas e na formação de professores e configura-se de interesse para a pesquisa educacional. Tomar o diálogo de forma equitativa entre diferentes conhecimentos, diferentes pessoas, diferentes práticas e formas de compreensão remete ao que Tubino (2002) tem definido como diálogo intercultural. Para o autor, na interculturalidade, “a palavra-chave é o diálogo". O diálogo pressupõe o reconhecimento e parte das desigualdades sociais, econômicas, políticas e de poder, com vistas a suprimi-las. Nesse sentido, investigar o processo de formação inicial e a reflexão das ações pedagógicas desenvolvidas, em um espaço escolarizado, possibilita uma compreensão sobre os diferentes aspectos do ensino e da aprendizagem de matemática, em que se pressupõe a formação do professor como pesquisador das próprias práticas, em busca de um diálogo, na perspectiva da educação intercultural.

$\mathrm{Na}$ formação desenvolvida no curso de Licenciatura Intercultural Indígena - Teko Arandu, na habilitação em matemática, a etnomatemática, é tratada numa perspectiva pedagógica. A etnomatemática, desenvolvendo estudos como teoria do conhecimento (D’AMBRÓSIO, 2008), configura-se como campo para o desenvolvimento de uma ação pedagógica que se pressupõe, que no encontro entre grupos de culturas distintos, são intercambiados conhecimentos, em uma prática dialógica.

É possível encontrar ao menos duas perspectivas de abordagem, para o conhecimento matemático. A matemática que tem sido tomada como paradigma do conhecimento a-contextual e transcultural. E outra, a perspectiva da etnomatemática, na qual o conhecimento matemático é tido como algo contextual e localmente construído como patrimônio que é das culturas que a têm desenvolvido. Os conhecimentos produzidos pelos povos indígenas Guarani e Kaiowá, que constituem diferentes modos de contar, medir, classificar e ordenar, são práticas de numeramento localmente construídas e que compõem os conhecimentos matemáticos desse povo. 
Desse modo, este trabalho apresenta a investigação realizada sobre as práticas de numeramento (MENDES, 2001), a partir das pesquisas dos estudantes indígenas, no processo de formação de professores indígenas na área de matemática. Procura, a partir dessas investigações, mostrar que o diálogo entre os conhecimentos matemáticos escolares e os matemáticos produzidos nas práticas vivenciadas pelos Guarani e Kaiowá, em suas áreas indígenas, pode contribuir para uma melhor organização da ação pedagógica do professor nas escolas indígenas.

Para Ponte, Brocardo e Oliveira (2013, p. 25), a caracterização de uma atitude investigativa de uma atividade matemática desenvolve-se habitualmente em três fases (em uma aula ou conjunto de aulas): introdução da atividade, a proposta por escrito ou oral; a realização da investigação individualmente, aos pares, em pequenos grupos ou com toda turma e, por último, a discussão dos resultados em que é relatado aos colegas o trabalho pesquisado; portanto, decorre de uma hierarquia metodológica para o trabalho de pesquisa.

Baseado nesses procedimentos iniciais das propostas dos autores, o trabalho de pesquisa realizado pelos alunos da Licenciatura Intercultural Indígena, habilitação em matemática, a partir do Projeto de Alternância ${ }^{1}$. Os procedimentos metodológicos para a investigação das práticas de numeramento partiu de uma orientação para que os alunos do curso estabelecessem um diálogo com os anciãos das aldeias. Os dados foram produzidos a partir do relato por escrito nas línguas portuguesa e guarani, realizado pelos alunos indígenas. A sistematização dos relatos e a avaliação das produções de dados, são tratadas na última parte deste texto.

\section{Etnomatemática e interculturalidade: os conhecimentos indígenas e os conhecimentos acadêmicos em um contexto escolar}

No Brasil, os povos indígenas passam por um intenso processo de transformação, que vão desde a desconfiguração territorial a mudanças de ordem econômica, social, política e cultural, por meio de diferentes processos, no qual a escolarização assumiu papel fundante. O processo arbitrário de escolarização, imposto aos povos indígenas, funcionou como um meio de anulação de identidades, marcado por uma ação brutal de colonização pautada no extermínio não só cultural, mas também físico de diversos grupos indígenas no Brasil.

A promulgação da Constituição Federal (CF) de 1988 trouxe uma mudança da relação do Estado brasileiro com os povos indígenas (BRASIL, 1988). Essas mudanças oficialmente decorrem

\footnotetext{
${ }^{1}$ O Projeto de Alternância constitui atividades proposto para o período do Tempo Comunidade do curso, onde os alunos desenvolvem pesquisas nas suas áreas indígenas.
} 
da forma como esse texto foi abordado em que marca o sujeito indígena na sociedade brasileira, colocando-o em outro lugar, no lugar de cidadão de direito, reconhecendo aos índios "sua organização social, costumes, línguas, crenças e tradições" (art. 231, $\S 1^{\mathrm{o}}$ ao $\S 7^{\circ}$ ), e seu direito originário a terra. No que tange à educação, reconhece em seus diferentes artigos "a utilização da língua materna e processos próprios de aprendizagem", e seus "modos de criar, fazer e viver" como patrimônio cultural imaterial (art. 210, $\S 2^{\circ}$, e art. 216).

É importante assinalar, também, a existência de um aparato legal sobre a Educação Escolar Indígena (EEI) surgido após a promulgação da CF de 1988. Esse aparato legal, que marca a reforma educacional ao longo dos anos de 1990, entrando no século XXI, pode dar uma dimensão de como vem sendo garantida, legalmente, uma educação específica e diferenciada que possibilita à EEI o estabelecimento de um espaço de diálogo de diferentes formas de conhecimento.

Destacam-se o Decreto presidencial n ${ }^{\circ} 26$, de 4 de fevereiro de 1991, que inclui as escolas indígenas no Sistema Nacional de Educação (BRASIL, 1991); a Lei de Diretrizes e Base da Educação (LDB) n 9.394, de 20 de dezembro de 1996, nos artigos 26, 32 e especificamente os artigos 78 e 79 (BRASIL, 1996); o Parecer 14, de 14 de setembro de 1999, do Conselho Nacional de Educação (BRASIL, 1999); a Resolução CEB n 3, de 10 de novembro de 1999/1999, que, entre outras disposições, cria a categoria de Escola Indígena (BRASIL, 1999); a Lei no 10.172, de 9 de janeiro de 2001, que aprova o Plano Nacional de Educação, traz um capítulo sobre Educação Escolar Indígena (BRASIL, 2001); o Decreto Presidencial n 6.861, de 27 de maio de 2009, que aborda a organização territorial da educação escolar sob a definição de territórios etnoeducacionais (BRASIL, 2009); a Resolução $\mathrm{n}^{\circ}$ 5, de 22 de junho de 2012, que estabelece as Diretrizes Curriculares Nacionais para a Educação Escolar Indígena na Educação Básica (BRASIL, 2012) e os Referenciais para a Formação de Professores Indígenas de 2001 (BRASIL, 2002).

Com as orientações de base legal, a escola indígena deveria ser um espaço onde os conhecimentos próprios e os científicos (tidos como universais) pudessem estar em diálogo. Pois seria um espaço de reconhecimento e valorização de diferentes formas de conhecer. Onde se poderiam estabelecer relações entre educação e interculturalidade. No entanto, mesmo com amparo legal, não se estabeleceram mudanças efetivas no sistema educacional.

A educação intercultural aparece nessas reformas educacionais, de acordo com Walsh (2010, p. 83), apenas como eixo transversal ou marco para introduzir a diversidade e o reconhecimento do "outro", "su intencionalidad no ha sido refundar o repensar los sistemas educativos, sino añadir y acomodar un discurso de la diversidad e interculturalidad -entendida como convivencia, 
tolerancia, respecto y reconocimiento de la diferencia cultural- sin mayor cambio.". Ainda para Walsh (2010), essa perspectiva de interculturalidade,

[...] seguindo as sugestões do filósofo peruano Fidel Tubino (2005) [...] se enraíza no reconhecimento da diversidade e diferença culturais, visando à inclusão desta no interior da estrutura social estabelecida. A partir desta perspectiva - que busca promover o diálogo, a convivência e a tolerância -, a interculturalidade é "funcional" ao sistema existente, não toca as causas da assimetria e desigualdade sociais e culturais, tampouco "questiona as regras do jogo", por isso "é perfeitamente compatível com a lógica do modelo neoliberal existente" (Tubino, 2005). (WALSH, 2010, p. 77-78, grifos da autora, tradução nossa).

O grande desafio hoje para a EEI e de pesquisadores, que atuam na discussão do currículo das escolas indígenas e na formação de professores indígenas, tem sido o estabelecimento de um projeto de ação educativa a partir de uma "interculturalidade crítica". Que, segundo Walsh (2010, p. 78), essa perspectiva “Apuntala y requiere la transformación de las estructuras, instituciones y relaciones sociales, y la construcción de condiciones de estar, ser, pensar, conocer, aprender, sentir y vivir distintas.". Para a autora, o entendimento do que seja a interculturalidade critica é um ponto importante, pois que ainda não existe. Ela tem sido entendida como uma estratégia, uma ação e um processo permanentes de relação e negociação "entre", em condições de respeito, legitimidade, simetria, equidade e igualdade (WALSH, 2010).

O que fica evidente é que as escolas indígenas não superaram as matrizes e estruturas vigentes do sistema educacional não indígena. Por exemplo, a matemática que se ensina nas escolas indígenas ainda tem sido tratada como um conhecimento neutro, com sua universalidade como ciência. E se ensina uma matemática a partir de uma racionalidade que não vão de encontro a diferentes práticas culturais. O ensino da matemática, nas escolas indígenas, não tem relação com a cultura local.

Desse modo, essa racionalidade, imposta a partir de uma lógica homogeneizadora, pode converter-se em um mecanismo de perda de identidade cultural, na medida em que, junto com a matemática, se ensinam e se aprendem padrões culturais estranhos às próprias culturas. A "matemática padrão", como chamada pelos indígenas quando se referem a matemática ensinada nas escolas.

Pensar em uma educação matemática que supere a racionalidade do saber científico eurocentrado é caminhar no sentido de um projeto de ação que possa estabelecer uma relação e negociação entre os conhecimentos próprios ou não cientifico e conhecimento acadêmico. Em 
condições de respeito, legitimidade, simetria, equidade e igualdade, com vistas a superar a visão de conhecimento, objetivo presente na forma de conceber a matemática. Nesse sentido, a etnomatemática tem se configurado como um potencial para se pensar uma ação pedagógica para as escolas indígenas sob a perspectiva de uma educação intercultural, fundada em um diálogo entre os saberes próprios e os saberes científicos. A etnomatemática, de acordo com D’Ambrósio (2008), tem como objetivo maior dar sentido a diferentes modos de saber e de fazer das várias culturas e reconhecer como e por que grupos de indivíduos, organizados como famílias, comunidades, profissões, tribos, nações executam suas práticas de natureza matemática.

A complexidade encontrada em estabelecer um diálogo entre os saberes tradicionais e os científicos se dá, entre outras razões, ao caráter da universalidade do saber científico, que não se aplica aos saberes tradicionais. Carneiro da Cunha (2009), ao trazer uma diferenciação entre saber científico e o tradicional (conhecimento próprio), adverte que o primeiro se afirma como verdade absoluta e se pretende universalizante. Enquanto que o segundo acolhe explicações divergentes cuja validade intenta ser puramente local.

O saber científico estabelece um regime único para o conhecimento, é hegemônico e se funda em conceitos objetivos. O saber tradicional pressupõe uma legião de regimes de conhecimento e se funda nas percepções. No entanto, ambos os conhecimentos são formas de procurar entender e agir no mundo. $\mathrm{O}$ valor dos conhecimentos tradicionais e dos científicos está justamente na sua diferença (CARNEIRO DA CUNHA, 2009).

Desse modo, quando se fala de práticas de numeramento, desenvolvidas pelos indígenas, as diferentes práticas de contagem, a partir da perspectiva da etnomatemática, remetem aos saberes próprios, pois estes acolhem diferentes explicações. Os povos executam suas práticas de natureza matemática, tais como contar, medir, comparar e classificar, de diferentes maneiras. Portanto, considerar a matemática como um produto cultural (D’Ambrósio, 2008) constitui um primeiro passo para uma aprendizagem significativa. Por outro lado, permite interpretar a diversidade cultural na sala de aula como fonte de riqueza para a aprendizagem. Nas aulas de matemática, deve haver espaço para negociação de significados e interação social.

Ao promover a formação de professores, de um grupo social culturalmente distinto, como os Guarani e Kaiowá, para atuarem na educação escolar indígena no ensino de matemática, tendo como projeto de ação educacional a perspectiva da interculturalidade crítica e da etnomatemática, é imprescindível levar em consideração as vivências no campo escolar dos alunos indígenas. Ao propor uma ação pedagógica na perspectiva da etnomatemática, o professor indígena poderá 
desenvolver distintas formas para diferentes ambientes culturais e sistemas de produção de conhecimento.

Assim, investigar as práticas de numeramento nas áreas indígenas abre novas abordagens, novos olhares e novas perspectivas do ensino da matemática para os indígenas Guarani e Kaiowá, subsidiando novos materiais didáticos para serem trabalhados no período da atuação docente. Para D’ Ambrósio (2008), inserir o aluno no processo de produção de seu grupo comunitário e social, e evidenciando a diversidade cultural e histórica em diferentes contextos, é fundamental para que este desenvolva uma cidadania crítica.

A percepção do processo de entender, analisar, produzir e disseminar os conhecimentos produzidos nas diferentes sociedades faz com que possa configurar uma educação escolar própria, seja indígena ou não. Segundo Scandiuzzi (2009, p. 18), “A transmissão gerontocrática do conhecimento matemático produzido e elaborado por esse povo há tantos anos, permanece no seu cotidiano e é mesclada com o conhecimento novo, [...] tanto na cultura indígena quanto na sociedade nacional".

Desta forma, alguns pontos podem ser pensados quando se discute as pesquisas voltadas para as práticas de numeramento dos povos indígenas guarani e kaiowá como:

1. As pesquisas realizadas no campo científico sobre as diversas formas de numeramento como dos povos indígenas, é a tentativa de preservar a própria identidade e a garantia à educação indígena escolar;

2. As trocas de experiências dessas práticas de contar propicia uma pluralidade de várias línguas entre os povos indígenas;

3. É o reconhecimento e a valorização da diversidade do Brasil;

4. Essas práticas de numeramento são usufruto da própria cultura indígena tão afetada pelas ações não indígenas;

5. A inclusão como contar utilizando a língua materna dá ênfase aos modos e ritmos de uma educação tradicional e que se produz num contexto doméstico e comunitário;

6. Não se leva em consideração o modelo assimilacionista tão prejudicial para os povos de diferentes culturas, pois o objetivo desse modelo é impor uma língua nacional para que as minorias sejam homogêneas;

7. As experiências passam de uma geração para outra, como formas de ensino da educação escolar indígena; 
8. Inclui-se assim o pensar na formação dos professores indígenas para a manutenção de suas práticas de contar que fazem parte do cotidiano dos povos indígenas e traz as novas formas de discutir como ensinar a matemática nos seus diversos contextos interculturais.

Os conhecimentos indígenas, por meio das práticas de numeramento, presentes no cotidiano de suas áreas indígenas, ressaltam a importância da diversidade étnica e linguística entre os povos indígena. Uma riqueza abafada pelas práticas não indígenas.

\section{Os conhecimentos indígenas: investigação de práticas de numeramento}

Nosso trabalho é desenvolvido no contexto da formação de professores indígenas das etnias Guarani e Kaiowá, do Estado de Mato Grosso do Sul. De acordo com o último censo do Instituto Brasileiro de Geografia e Estatística (IBGE, 2012), a população autodeclarada indígena, no Estado, tem uma estimativa de 73.295 habitantes, dos quais cerca de 50.000 são das etnias Guarani e Kaiowá e estão em áreas indígenas localizadas ao sul do Estado.

A maioria dessa população indígena, que vive nas aldeias, encontram-se em luta permanente pela ampliação de suas áreas e retomada dos territórios tradicionais. Esses territórios, denominados pelos Guarani e Kaiowá como tekoha (lugar onde se pratica o modo de ser e de viver), são considerados como lugar de resistência e de fortalecimento da identidade, marcada pelo Nandereko (modo de ser) que denomina um sistema complexo de práticas e conhecimentos.

As investigações no campo do ensino e aprendizagem da matemática, nas escolas indígenas das áreas dos Guarani e Kaiowá, têm constituído um modo de explorar e conhecer como os povos indígenas se apropriam dos conhecimentos próprios e se relacionam com os conhecimentos acadêmicos como um processo social das relações em que ocorrem no ambiente escolar. Na universidade, ao longo do processo de formação desses professores, esses conhecimentos defrontam-se em diferentes situações. E o estabelecimento do diálogo entre os conhecimentos tem se tornado um desafio contínuo para os professores formadores e para os alunos indígenas, como assevera Carneiro da Cunha (2009, p. 313): “A política acadêmica e a política étnica caminham em direções contrárias. Mas, a academia não pode ignorar que a 'cultura' ressurgindo para assombrar a teoria ocidental". Portanto, os conhecimentos tradicionais entram na universidade, nas nossas ações pedagógicas, mesmo que não tenhamos intencionalidade.

Assim, para que os conhecimentos tradicionais não sejam apagados, mas sim compartilhados, e que possibilitemos uma convergência entre esses conhecimentos, eles devem ser incorporados nos currículos escolares como parte da bagagem cultural dos alunos indígenas. De 
acordo com Ferreira (2000, p. 299), “os elementos culturais podem servir como ponto de partida para fazer e elaborar matematicamente no contexto intra-extraescolar", e assim são constituídas as práticas de numeramento.

As práticas de numeramento na perspectiva histórica foram criadas pelo homem ao longo dos anos como a sua capacidade de se orientar sobre o seu corpo e a contar com os dedos. Segundo Ifrah (1997, p. xix), “a mão é a primeira 'máquina de contar e calcular' de todos os tempos". Portanto, a enumeração concreta com a utilização de partes do corpo foi de fato recorrida por diversos povos, além de outros registros como pedras, conchas, pauzinhos, nó das cordas, entalhe em ossos e madeiras com desenho do traço em vertical, ábacos, entre outros.

Os conhecimentos produzidos pelos povos indígenas fazem parte da sua realidade. Contudo, no ambiente escolar, essa linguagem matemática não é utilizada somente no seio familiar, ou seja, não é recorrente em sala de aula. Para Santos (2009, p. 117), "a linguagem pode ser entendida como uma criação social que utiliza símbolos e também criados socialmente”. Assim, para estabelecer as relações entre os conhecimentos já construídos, a pesquisa, por meio da investigação realizada pelos docentes de matemática do Curso de Licenciatura Intercultural Indígena - Teko Aradu, junto com os estudantes indígenas, favorece uma amostra dos indícios desse método pelos Guarani e Kaiowá da região do sul do Estado de Mato Grosso do Sul.

Propomos, a seguir uma relação das práticas de contagem, presentes no viver cotidiano das áreas indígenas onde foram desenvolvidas as investigações. A Figura 1 ilustra o relato apresentado por um dos alunos, ao ouvir uma moradora da aldeia Pirakuá, de 80 anos. Ela conta a partir da oralidade e com gestos, utilizando os dedos e as pessoas para contar os números e meses. 


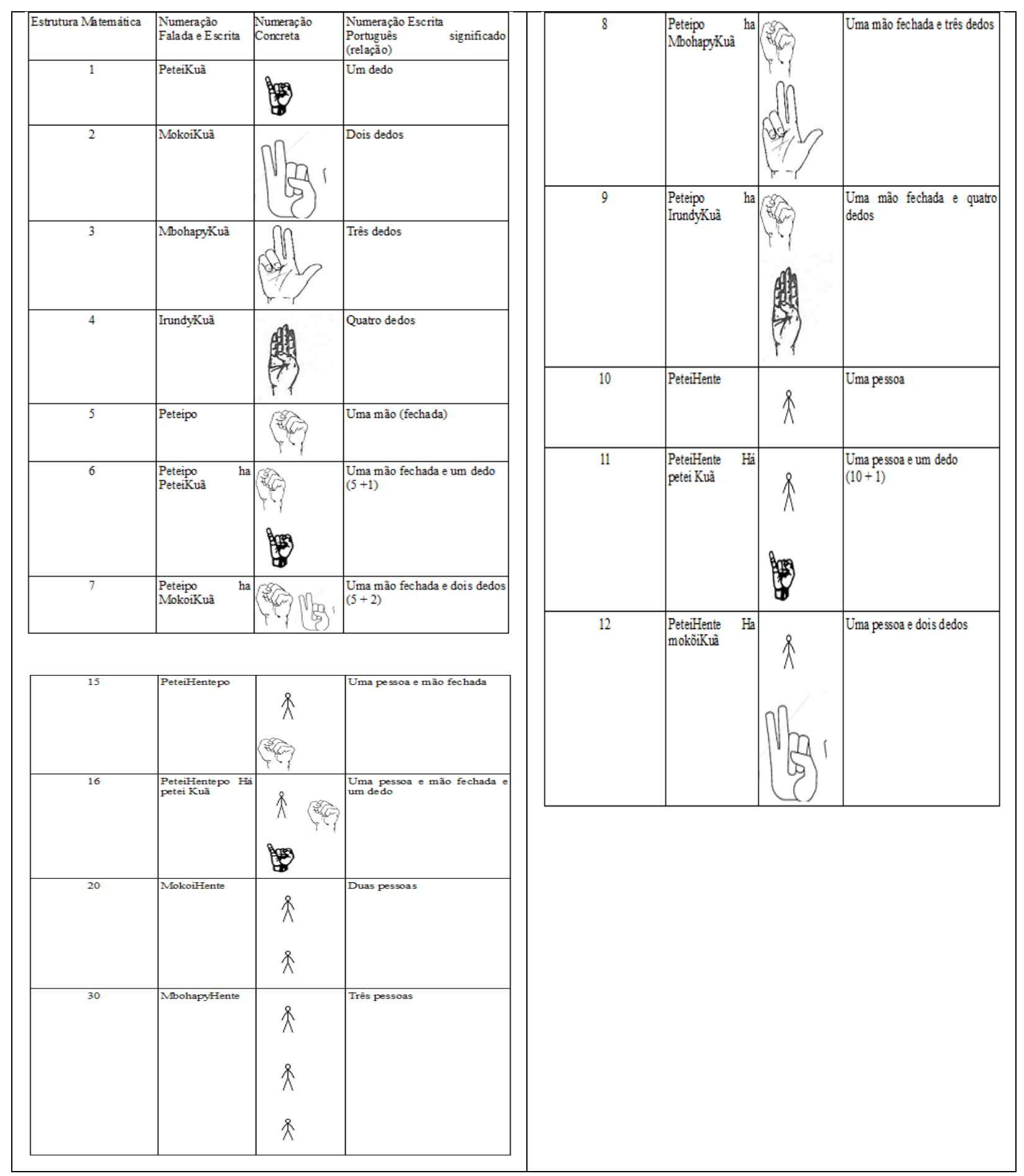

Figura 1 - Relato de uma moradora da aldeia Pirakuá, de 80 anos, mostrando como utiliza os dedos e as pessoas para contar os números e meses.

Nota: A mão fechada (cinco) e pelo dedinho mindinho (um). Contava apenas pelos números de dias dos meses simbolizando jasy ( $\mathrm{n}^{\mathrm{o}}$ de lua).

Os registros apresentados nesse relato simbolizam o emprego de palavras na língua guarani com a relação dedos e corpo total. Uma lógica que combina com formas de pensamento de 
civilizações não indígenas, mas se difere quando a relação do valor 10 equivale a uma pessoa e não aos dez dedos da mão.

Na prática, para discernir a quantidade, recorre à memória ou ao processo de comparação para instrumentalizar o método da contagem. Observa-se que os quatro primeiros números não têm nenhuma relação com outro na escrita Peteĩ, Mokoĩ, Mbohapy, Irundy, enquanto a partir do quinto, referente aos nomes dos números, há uma relação do que já foi registrado. Para o registro desse procedimento aritmético, entre os povos guarani, se usa a correspondência unidade a unidade, ou seja, biunívoca, uma vez que faz parte da enumeração concreta. Observa-se que a contagem da quantidade cinco se refere à mão fechada enquanto que alguns povos usam, para isso, a mão aberta.

Para Lins e Gimenez (2005, p. 39), esse processo também pode ser chamado de quantificação e o desenvolvimento dos sistemas de agrupamento. Estes procedimentos podem trazer contribuições para a aritmética e cultura. Imputa o valor social do aritmético e reconhece a existência de distintos tipos de cálculo. A criatividade é ponto favorável nas representações dos povos indígenas. Mesmo que estes procedimentos de contagem tenham uma limitação, pela necessidade da própria subsistência, no local em que está inserida, constituem-se em procedimentos aritméticos fundamentais.

Outro exemplo foi apresentado por um dos alunos e constitui relatos de uma moradora da aldeia Sassoró, de 84 anos, que, em suas práticas de numeramento, recorre a feijões e milhos para contar os dias trabalhados. Ela descreve essa prática a partir da narração de uma história.

Um indígena ${ }^{2}$ foi trabalhar sozinho em uma fazenda que tem muitos gados. O fazendeiro queria enganar o rapaz, mas desta vez o indígena é muito esperto. O rapaz tem serviço completa por 25 (vinte e cinco) dia de diária. E não consegui enganar o rapaz, porque o indígena tinha tudo anotado através do objeto e funcionavam assim: [...].

Essa senhora continuou narrando a história com gestos e mostrando no chão a prática desse trabalhador, que é apresentada na Figura 2 a partir das descrições feitas.

Nessa prática, utiliza uma lógica de contar que mobiliza a ideia de agrupamento. Entretanto, ressalta-se que, quando agrupa dez objetos de representação, há uma certeza de troca por outro objeto, representando a forma decimal.

Um terceiro relato foi apresentado por um aluno da aldeia Porto Lindo. Foi produzido por uma moradora, da referida aldeia, de 87 anos que disse utilizar palitos de madeira seca para representar a sequência numeral com origem no reko 1 a 9 (Figura 3).

\footnotetext{
${ }^{2}$ Que não sabia ler e escrever.
} 


\begin{tabular}{|c|c|c|c|}
\hline $\begin{array}{l}\text { Numeração escrita } \\
2\end{array}$ & Numeração concreta & $\begin{array}{l}\text { Significado em } \\
\text { Português } \\
\text { Dois dias de domingo } \\
\text { (o dia inteiro) }\end{array}$ & $\begin{array}{l}\text { Escrita } \\
\text { Guarani } \\
\text { Mokoi }\end{array}$ \\
\hline $1 / 2$ & & $\begin{array}{l}\text { Um domingoaté meio } \\
\text { dia }\end{array}$ & Petei \\
\hline 2 & & $\begin{array}{l}\text { Dois dias de sabado (o } \\
\text { dia inteiro) }\end{array}$ & Mokoiavati \\
\hline $1 / 2$ & & Um sábađo até meio dia & Peteiavati \\
\hline 4 & & $\begin{array}{l}4 \text { semana sendo que } 1 \\
\text { feijão carioquinha } \\
\text { significava } 1 \text { semana de } \\
\text { segunda a sexta feira } \\
\text { inteira de trabalho. }\end{array}$ & IrundyJasy \\
\hline
\end{tabular}

Figura 2 - Resultado matemático: total de 25 dias de trabalho para receber do fazendeiro.

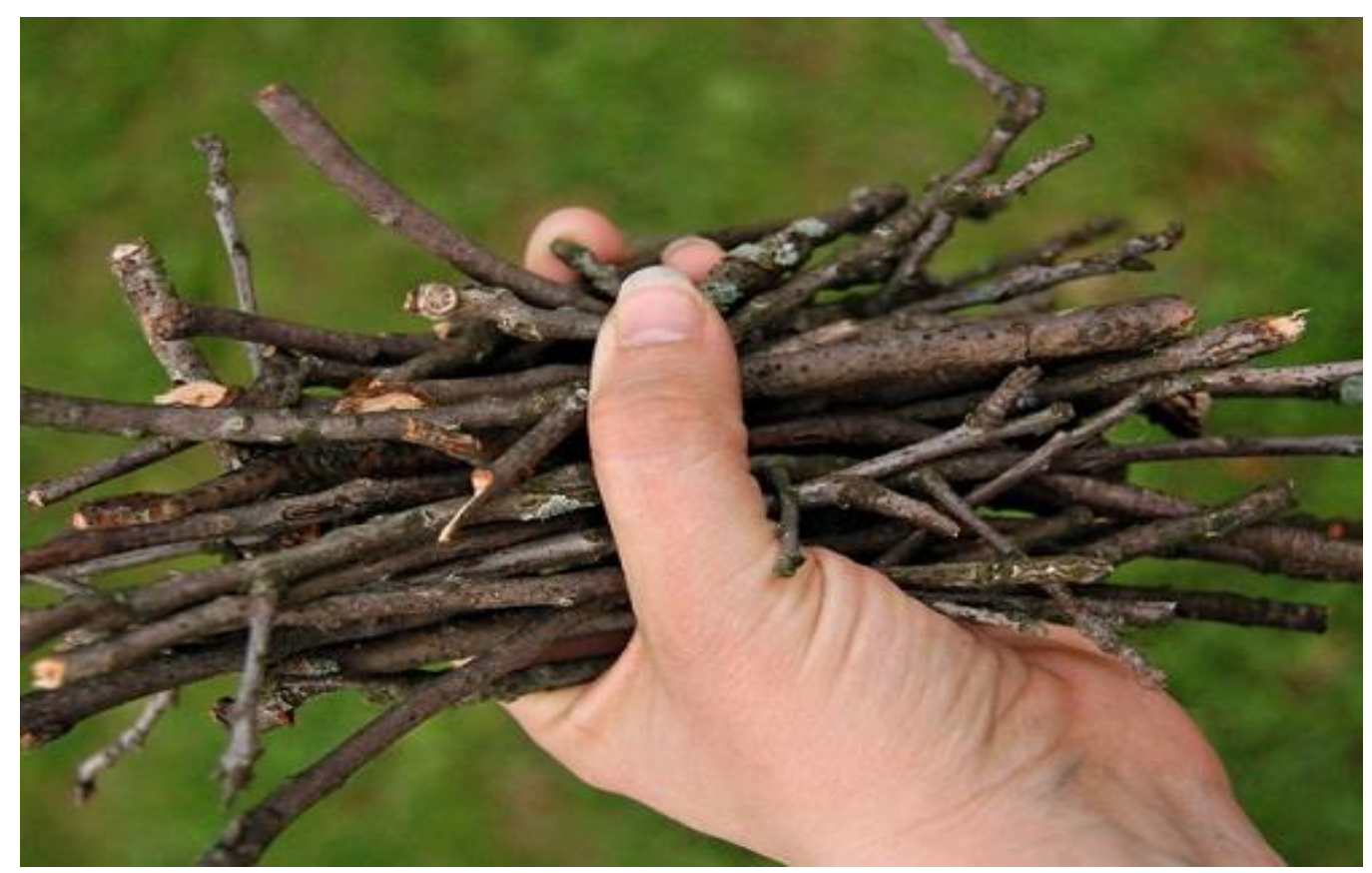

Figura 3 - Alusão a um punhado de ramos secos (numeração concreta). 
Fonte: Acervo da autora, 2015.

No Quadro 1, tentou-se organizar, a partir do relato apresentado, a relação que o narrador estabeleceu com a quantidade de gravetos e a contagem deles na língua guarani.

Quadro 1 - Relação entre a quantidade de gravetos e a contagem deles na língua guarani

\begin{tabular}{|c|c|c|}
\hline Numeração & Numeração em Guarani & Significado em Português \\
\hline 0 & Mba'eve & Nada \\
\hline 1 & Petei(pe =1ugar) & Um graveto \\
\hline 2 & Mokoi(mo prefixo) & Dois gravetos \\
\hline 3 & $\begin{array}{l}\text { Mbohapy(mo dar se mais } \\
\text { um) }\end{array}$ & Três gavetos \\
\hline 4 & irundy & Quatro grave tos \\
\hline 5 & $\begin{array}{l}\text { Po (quantidade dos dedos } \\
\text { da mão) }\end{array}$ & Cinco gravetos (saltar e salto) \\
\hline 6 & Potei(tei = por maisum) & Seis gravetos \\
\hline 7 & pokoi & Sete gravetos \\
\hline 8 & Poapy (apy = armazenar) & Oito grave tos \\
\hline 9 & Porundyrundy=conjuntos) & Nove gravetos \\
\hline 10 & pa & Dez gravetos/uma dezena \\
\hline 11 & patei & Onze gravetos \\
\hline 12 & pakoi & Doze gravetos \\
\hline 13 & $\mathrm{~Pa}$ apy & Treze gravetos \\
\hline 14 & Pairundy & Quatorze gravetos \\
\hline 15 & papo & Quinze gravetos \\
\hline 16 & Papotei & Dezesseis gravetos \\
\hline 17 & Papokoi & Dezessete gravetos \\
\hline 18 & Papoapy & Dezoito gravetos \\
\hline 19 & Paporundy & Dezenove gravetos \\
\hline 20 & Mokoipa & Vinte gravetos/duas dezenas \\
\hline 30 & Mohapypa & Trinta gavetos/três dezenas \\
\hline 100 & sa & Cem gravetos/ uma centena \\
\hline 1000 & su & M1 grave tos/ uma milhar \\
\hline
\end{tabular}

Nota: Lógica - Base 10; Mokoipa 2 de $10=20$; Mbohapypa 3 de $10=30$; Irundypa 4 de $10=40$; Popa 5 de $10=50$; Poteipa 6 de $10=60$; Pokoipa 7 de $10=70$; Poapypa 8 de $10=80$; 90 porundy de 9 de $10=90$.

Por fim, a pesquisa feita por uma aluna da aldeia Panambizinho, que apresentou a contagem conforme os Kaiowá a utilizavam antigamente (Quadro 2). Observa-se que a escrita da contagem de 1 a 4 é a mesma que a dos Guarani. A partir daí se introduz outra escrita para o cinco, e, na sequência, os números são escritos a partir de uma lógica de seis em seis. Essa forma de escrita também já havia sido apresentada por Lopez Samuel (1996). 
De acordo com o relatado pela aluna, há uma relação com a lua (contagem dos dias e as luas) e envolve o ciclo da plantação do milho. Cada passagem da lua refere-se à semana e aos meses.

Quadro 2 - Relação entre a quantidade de gravetos e a contagem deles na língua kaiowá

\begin{tabular}{|l|l|l|}
\hline $\mathbf{N}^{0}$ & Numeração escrita em Kaiowá & $\begin{array}{l}\text { Numeração escrita em } \\
\text { Português } \\
\text { Um }\end{array}$ \\
\hline 0 & Petei & Dois \\
\hline 2 & Mokoi & Três \\
\hline 4 & Mbohapy & Qua tro \\
\hline 5 & Irundy & Cinco \\
6 & Tenerõi & Seis \\
& Teiová & Sete \\
\hline 7 & TeiovárirePetei & Oito \\
\hline 9 & Teiováriremokoi & Nove \\
\hline 10 & Teiovárirembohapy & Dez/uma dezena \\
\hline 11 & Teiovájasy & Onze \\
20 & TeiovájasyPetei & Vinte \\
\hline & Teioravariremokõiteiovájasy & \\
\hline & &
\end{tabular}

$\mathrm{O}$ que se pode observar nas diferentes práticas de numeramento, relatadas a partir das pesquisas realizadas pelos acadêmicos, é que essas práticas assemelham-se a certas características do Sistema de Numeração Decimal (SND), ensinado de forma hegemônica nas escolas. Utiliza os princípios do SND, como o posicional, o agrupamento, aditivo, porque representam quantidades dependendo da posição da escrita, ou mesmo dos objetos utilizados para contagem. Outro princípio que se pode destacar, no desenvolvimento dessas diferentes práticas de numeramento, está relacionado, por exemplo, à necessidade decorrente da relação de trabalho com o não indígena. Também, a relação com objetos da natureza que é ligado a um conjunto de significados na língua guarani.

Colocam-se no centro da discussão sobre o ensino de matemática questões que podem auxiliar no ensino de estrutura de sistemas de numeração, mas, também, de outros valores e saberes que estão associados às práticas de numeramento desenvolvidas no modo de viver nas aldeias. Diferentes formas de representação dos processos de contagem, usadas, pelos Guarani e Kaiowá, estão relacionadas às práticas laborais, às relações com a sociedade do entorno e, em alguns casos, às formas de escrita já escolarizada. 
Os que se verificou nas escolas indígenas é que muitos desses conhecimentos ficam no universo da cultura e das práticas sociais e são pouco utilizados no processo de ensino e aprendizagem nas escolas indígenas. Conhecimentos que estão relacionadas ao mundo do trabalho, à relação com a sociedade envolvente e à cosmologia de cada grupo praticante. Essas práticas, trazidas para o âmbito da educação escolar, fazendo parte do currículo da escola, pode se dirigir a um estudo de diferentes potencialidades para o ensino da matemática, possibilitando o estabelecimento de atividades de aula e desenvolvimento do currículo de matemática.

\section{Considerações finais}

Quando se observa a forma em que os Guarani e Kaiowá utilizam a contagem nas suas práticas cotidianas, há uma lógica do pensamento matemático, própria, presente em suas práticas. $\mathrm{O}$ que observamos, na pesquisa em relação ao processo de contagem dos grupos indígenas onde foram realizados os estudos, pelos alunos, é que existem outras formas de conhecimento que não estão inscritas nos livros didáticos, no planejamento, no currículo da escola indígena. Isso fica evidenciado, quando olhamos para o currículo das escolas indígenas. Apesar de não ser objeto de estudo neste texto, este currículo, atende de modo geral, a orientações curriculares apresentada de forma homogênea para todo o sistema educacional brasileiro.

Assim, envolver os alunos dos cursos de formação em um projeto de ação na perspectiva da educação intercultural crítica e da etnomatemática é um desafio que perpassa os cursos de formação de professores indígenas. Compreender as possibilidades de diálogo entre saberes próprios, considerando que são de natureza diferente, pode ser um caminho, para uma Educação Escolar Intercultural.

É preciso pensar no currículo para as escolas indígenas com a concepção de respeito ao outro, às suas diferenças, o seu cotidiano, à sua língua, os seus costumes, às suas crenças, saberes tradicionais para a valorização do ensino e aprendizagem de matemática. Com vistas à transformação das assimetrias sociais, existentes no contexto da formação de professores indígenas, e das relações de poder nas escolas indígenas.

\section{Referências}

BRASIL. Constituição (1988). Diário Oficial [da] República Federativa do Brasil, Brasília, DF, 5 out. 1988. n. 191-A, p. 1. Disponível em:

<http://www.planalto.gov.br/ccivil_03/Constituicao/Constituicao.htm >. Acesso em: 20 jan. 2016. 
. Decreto $n^{\circ}$ 26, de 4 de fevereiro de 1991. Dispõe sobre a educação indígena no Brasil. Brasília, DF, 1991. Disponível em: <http://www.planalto.gov.br/ccivil_03/decreto/19901994/D0026.htm>. Acesso em: 20 jan. 2016.

. Decreto $n^{0}$ 6.861, 27 de maio de 2009. Dispõe sobre a Educação Escolar Indígena, define sua organização em territórios etnoeducacionais, e dá outras providências. Brasília, DF, 2009. Disponível em: 〈http://portal.mec.gov.br/sesu/arquivos/pdf/leis2.pdf〉. Acesso em: 20 jan. 2016.

. Lei 10.172, de 9 de janeiro de 2001. Aprova o Plano Nacional de Educação e dá outras providências. Brasília, DF, 2001. Disponível em:

<http://portal.mec.gov.br/sesu/arquivos/pdf/leis2.pdf>. Acesso em: 20 jan. 2016.

. Lei no 9.394, de 20 de dezembro de 1996. Estabelece as diretrizes e bases da educação nacional. Brasília, DF, 1996. Disponível em:

<http://www.planalto.gov.br/ccivil_03/Leis/L9394.htm>. Acesso em: 20 jan. 2016.

. Ministério da Educação. Conselho Nacional de Educação. Câmara de Educação Básica. Parecer no 14, de 14 de setembro de 1999. Diretrizes curriculares nacionais da educação escolar indígena. Brasília, DF, 1999. Disponível em: <http://portal.mec.gov.br/sesu/arquivos/pdf/leis2.pdf〉. Acesso em: 20 jan. 2016.

Resolução CEB no 3, de 10 de novembro de 1999. Fixa

diretrizes nacionais para o funcionamento das escolas indígenas e dá outras providências. Brasília, DF, 1999. Disponível em: <http://portal.mec.gov.br/cne/arquivos/pdf/CEB0399.pdf>. Acesso em: 20 jan. 2016.

Resolução $n^{0}$ 5, de 22 de junho de 2012. Define diretrizes curriculares nacionais para a educação escolar indígena na educação básica. Brasília, DF, 2012. Disponível em: <http://mobile.cnte.org.br:8080/legislacao-externo/rest/lei/86/pdf>. Acesso em: 20 jan. 2016.

. Secretaria de Educação Fundamental. Referenciais para a Formação de

Professores Indígenas. Brasília, DF, 2002. Disponível em:

<http://portal.mec.gov.br/seb/arquivos/pdf/Livro.pdf>. Acesso em: 20 jan. 2016.

CARNEIRO DA CUNHA, M. Cultura com aspas. São Paulo: Cosac \& Naify, 2009. 
D’AMBRÓSIO, U. O programa etnomatemática: uma síntese. Acta Scientiae, Canoas, v. 10, n. 1, p. 7-16, jan./jun. 2008.

FERREIRA, M.K.L. (Org.). Ideias matemáticas de povos culturalmente distintos. São Paulo: Global; Mari/USP, 2002. 336 p. (Antropologia e Educação).

IBGE-Instituto Brasileiro de Geografia e Estatística. Tabela 4 - População autodeclarada indígena, da participação relativa no total da população do estado e total da população autodeclarada indígena no País, segundo as Unidades da Federação - 2010. Rio de Janeiro, 2012. Disponível em: <http://www.ibge.gov.br/indigenas/indigena_censo2010.pdf>. Acesso em: 20 jan. 2016.

IFRAH, G.. História universal dos algarismos: a inteligência dos homens contada pelos números e pelo cálculo. Rio de Janeiro: Nova Fronteira, 1997. t. 1.

LINS, Romulo Campos; GIMENEZ, Joaquim. Perspectivas em aritmética e álgebra para o século XXI. 6. ed. Campinas: Papirus, 2005.

LOPEZ, S. Educação matemática indígena: um estudo etnomatemático com os índios guaranikaiowá do Mato Grosso do Sul. Dissertação (Mestrado)- Setor de Educação, Universidade Federal do Paraná, Curitiba, 1995. Lopes Belos (1996)

MENDES, J. R. Ler, escrever e contar: práticas de numeramento-letramento dos Kaiabi no contexto de formação de professores índios no Parque Indígena do Xingu. 2001. Tese (Doutorado em Linguística Aplicada) - Instituto de Estudos da Linguagem, Universidade Estadual de Campinas, Campinas, 2001.

PONTE, J.P.da; BROCARDO, J.; OLIVEIRA, H. Investigações matemáticas na sala de aula. Belo Horizonte: Autêntica, 2013.

SANTOS, Vinício Macedo. Linguagem e comunicação na aula de matemática. Belo Horizonte: Autêntica, 2009. p. 117-125.

SCANDIUZZI, P. P. Educação indígena x educação escolar indígena: uma relação etnocida em uma pesquisa etnomatemática. Marília: Editora UNESP, 2009. 
TUBINO, F. Entre el multiculturalismo y la interculturalidad: más allá de la discriminación positiva. In: FULLER, Norma (Ed.). Interculturalidad y política: desafíos y posibilidades. Lima: Red para el Desarrollo de las Ciencias Sociales el Perú, 2002. p. 51-76.

WALSH, C. Interculturalidad crítica y educación intercultural In: VIAÑA, Jorge; TAPIA, Luis;

WALSH, Catherine. Construyendo interculturalidad crítica. La Paz, Bolívia: III-CAB; Instituto Internacional de Integración del Convenio Andrés Bello, 2010. p. 75-96. Disponível em:

$<$ http://datateca.unad.edu.co/contenidos/401596/2015_1/

Interculturalidad_Critica_y_Educacion_Intercultural.pdf $>$. Acesso em: 20 nov. 2014.

Recebido em: 01.06.2016

Aceito em: 28.08.2017 